\title{
Professional Competence PeER ReVieW AND QUALITY ASSURANCE IN ENGLAND AND WALES AND IN SCOTLAND
}

\author{
AVROM SHERR* AND ALAN PATERSON ${ }^{* *}$
}

\begin{abstract}
Peer review has emerged as a method of assessing the work of legal aid lawyers in the United Kingdom. The authors show how testing different methods led to review of files emerging as the most effective means of peer review. A number of approaches, including double marking of files, are used to ensure accuracy and consistency among the reviewers. Peer review in Scotland may be more relevant than England and Wales to the Canadian context as the legal professions are of similar size. The authors discuss both criminal and civil work and the application of peer review as well as the outcomes of the pilot projects in the U.K.
\end{abstract}

La révision interne est devenue une méthode d'évaluation des avocats de l'aide juridique au Royaume-Uni. Les auteurs démontrent qu'en faisant l'essai de plusieurs méthodes, ils en sont venus à déterminer que la revue de dossier était la méthode la plus efficace de révision interne. Un certain nombre d'approches, incluant le double marquage de dossiers sont utilisées pour assurer la précision et l'uniformité des réviseurs. La révision interne en Écosse s'applique peut-être davantage au contexte canadien que celle qui se pratique en Angleterre et au pays de Galles étant donné que les professions juridiques sont de taille comparable. Les auteurs discutent de dossiers pénaux et civils ainsi que de l'exécution de la révision interne et des conclusions des projets pilotes au R.-U.

\section{TABLE OF CONTENTS}

\section{The EMERgence of PeER Review IN THE}

LEgAL PROFESSION . . . . . . . . . . . . . . . . . . . . . . . 152

II. PeER REVIEW In ScotLAnd . . . . . . . . . . . . . . . . . . . . 155

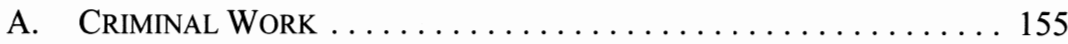

B. Civil Work ............................. 158

III. Peer REVIEW In ENGLAND ANd Wales $\ldots \ldots \ldots \ldots \ldots \ldots \ldots \ldots 160$

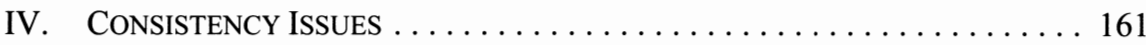

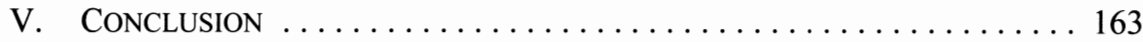

* Avrom Sherr, Woolf Professor of Legal Education, Institute of Advanced Legal Studies, University of London, United Kingdom.

* $\quad$ Professor Alan Paterson is Director of the Centre for Professional Legal Studies (an independent think tank focusing on access to justice and the legal profession) at Strathclyde University Law School, Scotland. He is the Chair of the International Legal Aid Group; Chair of the Legal Aid and Legal Services Group of the International Working Group on Comparative Legal Professions; Chair of the Legal Services Group of Citizens Advice Scotland; Research Adviser to the Scottish Legal Aid Board (responsible for the training and monitoring aspects of the peer review of legal aid lawyers in Scotland). $\mathrm{He}$ is a qualified solicitor in Scotland (1980). He has conducted numerous empirical research projects in relation to the provision of legal services in the U.K. for the Scottish Executive, the ESRC, the Leverhulme Trust, the Nuffield Foundation, the Scottish and National Consumer Councils, the Scottish Legal Aid Board and the English Legal Services Commission. 


\section{The Emergence of Peer Review in the Legal Profession ${ }^{1}$}

This article examines the emergence of peer review as the primary method of auditing and assessing the work of legal aid lawyers in the United Kingdom. After explaining the approaches piloted in previous research, the article details the current method of peer review on files, the generating of criteria for assessment, and the marking scheme adopted. The article then goes on to look at the differences between peer review in Scotland and England and Wales and gives early information on outcomes. The article concludes with some thoughts on how research is likely to be taken forward.

The article begins by explaining professional peer review ${ }^{2}$ where a panel of independent, experienced practitioners assesses the quality of work of other professionals against a set of criteria and levels of performance agreed upon by the professional community, is being used in Scotland, as well as England and Wales, to review the work of legal services lawyers paid for by the public purse. Concern about maintaining the standard of work under conditions of a steady decrease in payment has been widely expressed by members of the legal profession. It has become necessary to ensure quality whilst fixed fees become the norm, regulations and procedures change, and new generations of lawyers enter the market. The system of peer review has focused on a range of factors including inputs, structure, process, and outcomes. It has also begun by testing out a range of different approaches, including direct observation, indirect observation (for example, through an examination of video recordings), audio tapes, third party report, and the scrutiny of files. ${ }^{3}$

All approaches to measuring the competence of legal practitioners have their difficulties. Direct observation ${ }^{4}$ might appear the simplest and most straightforward, but it presents a range of practical and logistical problems. Court lawyers frequently experience continuations or postponements of hearings or trials. If a peer reviewer has been assigned to review that lawyer on a particular day, there may be nothing to assess because each of that lawyer's cases has been postponed. ${ }^{5}$ If the observation is of a lawyer/client interview, then there may be problems of intrusiveness or client consent. Indirect observation may be impractical since all parties, including the state, may not agree to videotape or audio tape proceedings that take place in the courts or a lawyer's office. ${ }^{6}$

1 This part of the article draws heavily on Richard Moorhead et al., Quality and Cost: Final Report on the Contracting of Civil, Non-Family Advice and Assistance Pilot (London: The Stationery Office, 2001). This article was presented to the Law Society of Alberta 100th Anniversary Conference, entitled "Canadian Lawyers in the 21 st Century" in October 2007, and has benefited from comments made by the Editors of this Review, especially, Alice Woolley.

For the definition of peer review as used in this article, see ibid., c. 5.

See Avrom Sherr, Richard Moorhead \& Alan Paterson, Lawyers, The Quality Agenda: Assessing and Developing Competence in Legal Aid (London: Her Majesty's Stationery Office, 1994), c. 2, 3.

4 Hazel Genn \& Yvette Genn, The Effectiveness of Representation in Tribunals: Report to the LordChancellor (London: Lord Chancellor's Department, 1989).

5 See also Lee Bridges et al., Evaluation of the Public Defender Service in England and Wales (London: The Stationery Office, 2007) at 23.

6 Videotaping of court proceedings is rare in the U.K., though work on interviews has been more productive. See e.g. Avrom Sherr, "Clients Are People Too" The Law Society's Gazette 83 (29 November 1986) 3563; Avrom Sherr, "Lawyers and Clients: The First Meeting" (1986) 49 Mod. L. Rev. 323; Avrom Sherr, Client Care for Lawyers: An Analysis and Guide, 2d ed., (London: Sweet \& Maxwell, 1999). 
Third-party reporting, where peers interrogate knowledgeable third parties, has been used sparingly and to limited effect. Judges, perhaps the most obvious third parties, have shown little enthusiasm to date for systematic involvement in the assessment of individual court lawyers. Perhaps this is because they fear that it might destabilize the delicate balance of understandings between the bench and the bar, which they consider to be important for the smooth operation of the courtroom. Or perhaps they are aware that making judgments of this nature is fraught with difficulties when they also need to adjudicate on clients and cases before them. ${ }^{7}$

Model or standardized clients ${ }^{8}$ on the other hand, have been used in a number of studies of doctors and lawyers, ${ }^{9}$ although for the reasons stated in earlier research, ${ }^{10}$ they can only assess certain aspects of the quality of service which they receive. Furthermore, using standardized clients can raise ethical issues unless the lawyers have agreed to receive unidentified model clients in a specified time period. ${ }^{11}$

Given the problems associated with these approaches, it is understandable that the majority of peer review programs rely principally on case file review against agreed upon criteria. Although issues of client confidentiality can arise, they are generally less intrusive than those raised by observation. Moreover, files are easier to make available to reviewers (especially if the case has closed), thus reducing the cost of the program. ${ }^{12}$ At the outset of peer review in England and Wales, concerns were voiced that in criminal cases or cases where barristers were involved, there might be relatively little on the file for the reviewers to assess. This has not proved to be the case. ${ }^{13}$

Having specified the aspects of the service which will be reviewed, and the subject of the review itself, there is then the need to assimilate these factors and generate specific criteria for evaluating quality of performance. ${ }^{14}$ Criteria can be aimed at: communication issues; client care; legal competence; appropriateness; completeness; clarity; correctness and involvement.

8 1.

However, current considerations in England and Wales of assessment of advocates includes judicial These are typically actors who have been trained by researchers to present the same case history to a range of different lawyers. By keeping the input constant any variations in the performances of the lawyers can more fairly be attributed to differences in lawyering.

Moorhead et al., supra note 1; Richard Moorhead, Avrom Sherr \& Alan Paterson, "Contesting Professionalism: Legal Aid and Nonlawyers in England and Wales” (2003) 37 Law \& Soc'y Rev. 765. On the use of standardized clients in clinical legal education, see Karen Barton et al., "Valuing What Clients Think: Standardized Clients and the Assessment of Communicative Competence" (2006) 13 Clinical L. Rev. 1.

See e.g. Moorhead et al., ibid., c. 7.

This was the approach used in England and Wales, where providers of legal services who wished to obtain a contract to provide legal aid services from the Legal Services Commission had to agree to receiving unidentified model clients during the period of the contract: see Moorhead et al., supra note

The major cost involved with peer review is paying the fees or salaries of the reviewers.

The experience of the pilot peer review program into the quality of the work done by public defenders in Scotland similarly indicated that there was sufficient information on their files to permit assessment of the quality of their work. See Part III of the article below.

It is essential to involve the peer reviewers in the generation and agreement of these criteria, and the evidence necessary to satisfy them, once they have seen a range of files and identified the types of issue that can be assessed by looking at files and talking to legal advisers. 
timeliness of advice; management systems; strategy and resource allocation; professional threshold requirements (such as conduct rules); appropriateness of work as well as accuracy and approach, adequate staff supervision and management; the impact of failures (or successes) on the clients in question; and recording all of the above. As a result, the criteria can lead to long, exacting lists. However, there is inevitably a trade-off between the length of such lists, the consistency of reviewer's marking, and the number of files a peer reviewer can look at. There is also a trade-off in the opposite direction between consistency and validity: a reviewer needs to look at a certain number of files to be satisfied that a valid judgment can be made. The law of diminishing returns ensures that reducing the number of criteria that can be answered increases the number of files than can be looked at, but if taken too far, may also reduce the consistency of the judgment, in turn reducing its validity.

What is needed is a balance, and trial and error ${ }^{15}$ suggests that the optimum number of criteria for reviewers to work with is something in the region of twenty. This result argues for a focused approach on limited aspects of service by the peer reviewers, or a set of more general concepts which can be addressed in different ways depending on the subject matter under consideration.

The two sets of criteria used in England and Wales for civil cases (including family law) and crime are excerpted in Annexes A and B to this article as examples of different approaches to evaluation criteria. As will be seen, the civil criteria are posed at a rather more generic level whilst the crime criteria are more specific. The gradings used in both are:

$1=$ excellent

$2=$ competence plus/good

$3=$ threshold competence

$4=$ not competent/poor

$5=$ non-performance/very poor

$\mathrm{X}=$ insufficient information to make a judgment

$\mathrm{NA}=$ not applicable

As will also be seen, the desirability of reviewers commenting on the overall quality of the work done in a case "in the round" suggests that in addition to assessing files against individual criteria, reviewers should also be able to award an overall mark to the case. A further challenge for reviewers then is the marking scheme to be adopted. While this could be a simple pass/fail standard, an issue would still remain as to where to set the pass mark. Much depends on the purpose for implementing peer review and quality assurance. If the aim is to "weed out" poorly achieving practitioners from poverty legal services programs, a pass/ fail standard at the level of minimum competence will suffice. If, however, quality assurance has wider goals, including the raising of professional standards over time, the review process should contain positive reinforcement where the practitioner demonstrates good practice and 
the pass/fail standard may be adjusted over time. This might then need a Likert Scale of Achievement. ${ }^{16}$

Peer review programs for poverty legal services lawyers in the U.K. have utilized the quality continuum set out in Figure $1 .{ }^{17}$ In England and Wales, as indicated above, files are marked on a five point scale $(5=$ non-performance, $4=$ inadequate professional services, $3=$ threshold competence, $2=$ competence plus, and $1=$ excellence). By placing the pass mark at around threshold competence at the outset, the schemes allow service providers to get used to a quality assurance regime whilst leaving room for quality enhancement over time. In addition, there is a risk that if the pass mark was placed higher up the scale, competent providers would be lost to the service and access problems or "advice deserts" 18 created.

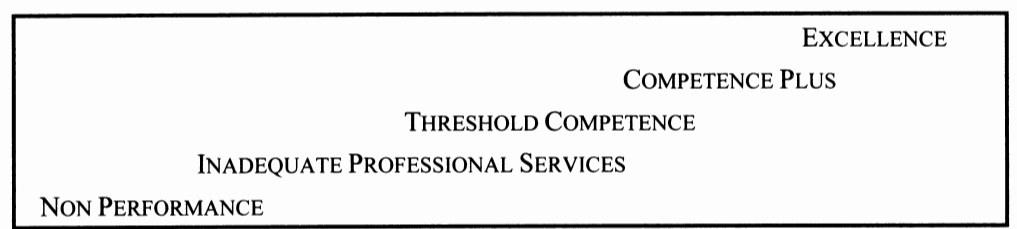

Figure 1: The Performance Continuum

Finally, in order to maximize the fairness and validity of peer review, it is necessary to select reviewers who are independent persons with significant current or recent practical experience in the area(s) being reviewed, to involve them in the development of the criteria and the assessment protocol, and also to train them in both on actual files. To ensure ongoing consistency amongst the reviewers, it has become accepted practice to implement double marking of a proportion of the files to be reviewed. ${ }^{19}$

\section{Peer Review in Scotland}

\section{A. Criminal Work}

Although the work of peer review began chronologically in England and Wales before it started in Scotland and the main research was carried out in England and Wales, this article looks first (and mainly) at Scotland since the example of Scotland may be more relevant in the Canadian context. The larger legal profession in England and Wales is more specialized and more differentiated than that of Scotland. The Canadian context is also often quite rural

See Rensis Likert, "A technique for the Measurement of Attitudes” (1932) 140 Archives of Psychology 1.

This continuum was developed by Alan Paterson and Avrom Sherr in Sherr, Moorhead \& Paterson, supra note 3.

In the U.K. in the last few years, anecdotal evidence has begun to emerge suggesting that in some parts of the country, particularly in rural areas, a shortage of private lawyers is occurring who are willing to undertake work for legal aid clients because of the low rates of remuneration from the state for such work. See e.g. Pascoe Pleasence, Alexy Buck \& Nigel J. Balmer, eds., Transforming Lives: Law and Social Process: Papers from the Legal Services Research Centre's International Research Conference, Transforming Lives, Queen's University, Belfast 19th to 21st April, 2006 (London: The Stationery Office, 2007). 
and the smaller numbers within the profession may be similar. The Scottish Legal Aid Board's (SLAB) first foray with peer review was related to the work of the Public Defence Solicitors' Office (PDSO). This was the newly fledged public defender service for Scotland, which built upon an earlier pilot project that lasted from 1998 to $2003 .{ }^{20}$ Although the service consisted of approximately ten salaried lawyers employed by the SLAB (there are around 600 lawyers in private practice who are registered to do criminal legal aid work), it provides a useful benchmark for the SLAB when assessing the work and cost of the private profession.

In part to address issues of quality which were unresolved after the review of the pilot project, ${ }^{21}$ in early 2003 the SLAB established a working party to draft a set of peer review criteria for assessing the work of the public defence lawyers undertaking summary criminal work. ${ }^{22}$ The draft criteria were revised by leading practitioners and then tested with a further group of established practitioners at a workshop at the end of March 2003. Following discussion of the criteria, they were tested against a range of case files with the practitioners working in pairs. After training, the pairs attained a high degree of consensus. The markers decided that it was sufficient for each of the individual criteria to be marked against a threefold scale of (1) "below requirements," (2) "meets requirements," and (3) "exceeds requirements." It was also agreed that there should be provision for two other possible answers, namely: (4) "C" or "can't assess" (meaning that there is insufficient information on the file for the reviewer to assess) and (5) "N/A" or "not applicable" (meaning that in the particular situation of the case being reviewed that criterion is inapplicable). Finally, it was agreed that, as in England and Wales, an overall mark should be assigned to the file and that this should be on a fivefold scale, approximating to the five levels set out in Figure 1, with a " 1 " score being so poor as to be almost non-performance and a " 5 " score being excellent. This overall mark would not be the product of a mathematical averaging, but rather of the reviewer's professional judgment bearing in mind a common set of marking protocols. A comments section was added to the end of each criterion and at the end of the overall file report. These sections provided a few lines for remarks from the reviewer to explain either the overall mark given to the file or any failing scores on individual criterion. The SLAB also determined that 25 percent of files should be double marked to enable marker consistency to be assessed and maintained.

By the end of the development phase the practitioners and the SLAB came to the conclusion that:

(1) Despite the early skepticism in a number of quarters that Scottish criminal lawyers would not keep detailed enough records on their files to enable a peer reviewer to assess what had been happening in summary cases, the workshop had demonstrated that the criteria could be applied without significant difficulties to the PDSO files;

(2) The criteria could be applied consistently by different markers and such areas of significant disagreement in the scoring that emerged could largely be attributed to

20 See Tamara Goriely et al., The Public Defence Solicitors' Office in Edinburgh: An Independent Evaluation (Edinburgh: Scottish Executive Central Research Unit, 2001).

Ibid.

"Summary" here refers to the procedure adopted for less serious offences in Scots Criminal law. 
differences in knowledge and local legal culture ${ }^{23}$ between the reviewer and the original file handler;

(3) These differences in local legal culture could affect the scoring on the criteria, but the effect of these could be counteracted by the training of the reviewers, using the comments section at the end of the form, and providing an opportunity for the lawyers whose work was being reviewed to respond to fail scores on particular criteria;

(4) If the pilot phase threw up any significant problems, there might be some merit in exploring some limited use of customer satisfaction surveys ${ }^{24}$ and observation ${ }^{25}$ as supplementary measures; and

Overall, peer review based on using files, even in the criminal legal aid field, was a valid and acceptably reliable method for assessing the quality of case handling in criminal legal aid cases provided that peers of appropriate experience are selected, that reviewers are given appropriate training, and that provision is made for feedback from the staff being reviewed.

Subsequently, the SLAB implemented a pilot program of reviewing files from the PDSO with the help of two of the trained peer reviewers. The results of this pilot program over nine months were considered at a further seminar for the reviewers and the Head of the PDSO at the end of August 2004. It was clear that one of the markers had awarded an overall "fail" mark to considerably more files than the other. As may also occur with variations in gradings by different academic markers, an examination of the double marking of the same files by the two reviewers revealed that they had taken significantly different approaches to two key matters. The first was in relation to omissions from the files. ${ }^{26}$ It was agreed that a broader brush approach was preferable in criminal cases where there was a tendency for less to be written down than in civil cases. ${ }^{27}$ The second difference stemmed from a difference in the pass/fail standard which they were applying. One had applied the equivalent to a minimum adequate performance (see Figure 1) while the other had applied a higher pass mark. It was

24 However, it was noted that the research on the pilot public defender project had encountered considerable difficulties in trying to implement a customer satisfaction survey, due to an inability to track sufficient numbers of accused persons or to persuade them to assist with the research: see ibid. Up until the workshop it had been thought first, that it might be necessary to amplify the information on the file through observation in order to answer some of the criteria, and second, that there would be severe practical problems in carrying out such observation. The option of following an individual Public Defence Solicitors' Office (PDSO) lawyer around the courts on a particular day was not considered to be a practical one but it was felt that if the PDSO had several cases coming before the same sheriff on a particular day there might be merit in an observer watching a whole morning, thus enabling them to take account of factors such as the mood of the sheriff and the co-operativeness of the fiscal. was nothing on the file, but nothing to suggest that the point had not been covered, and nothing appeared to hinge in that case on its presence or absence then she would award a "2" rather than a "C." In relation to assessment protocols it was agreed that in the light of the broad brush approach the appropriate rule of thumb to be applied to the scoring of files would be that 3 or more "1"s or "C"s would prima facie lead a file to fail, unless in the reviewer's professional judgment, the failures or omissions, did not justify the file failing. 
agreed that the pass/fail standard for a file should be set at the lower level, that of the competence of the solicitor of ordinary skills (equivalent to the test for professional negligence. This approach has not been taken in England and Wales). ${ }^{28}$

With these matters resolved, a series of additional files were marked and a high degree of uniformity achieved. The seminar attendees concluded that the robustness of peer review in relation to summary criminal files had been demonstrated. Armed with this conclusion, the SLAB, with the backing of the Scottish Executive, initiated three-way negotiations between the Law Society, the Scottish Executive, and the SLAB, over extending peer review in criminal cases from the files of the PDSO service to the legal aid files of the private profession in both summary and solemn ${ }^{29}$ cases. Essentially what was on offer was an increase in fees for criminal legal aid work in return for quality assurance in the shape of peer review. Although this proposal was accepted by all three parties in principle, the details have taken many months to resolve. At this time, a version of the peer review criteria for solemn and summary cases has largely been agreed upon, and plans are in place to pilot these on anonymous files. ${ }^{30}$

\section{B. CIVIL WORK}

\section{THE BACKGROUND}

While the criminal negotiations were dragging on, following separate and rather speedier negotiations between the Scottish Executive, the SLAB, and the Law Society, it was agreed between the three parties that peer review would be introduced from October 2003 for all civil legal aid and advice and assistance practitioners in Scotland. In return for an increase in fees for civil legal aid work, the profession had accepted quality assurance in the shape of peer review. A total of 752 firms (out of a total of 1,200 or so legal firms in Scotland in 2003) were registered to provide civil legal aid or advice and assistance and a rolling review of all these firms commenced on 1 July 2004, which was scheduled to be completed by October 2006. In practice, the cycle of all civil legal aid firms was effectively completed by December 2006. The process is administered by the Quality Assurance Committee of the

Known in Scotland as the "Hunter v. Hanley" test after the leading case which established the negligence standard there: Hunter v. Hanley, 1955 S.C. 200.

29 The procedure adopted for more serious crimes in Scotland, which involves a jury.

30 The quality assurance of Scottish lawyers doing criminal defence work will not in the future be restricted, as it currently is, to the ranks of solicitors. It seems that advocates are likely to follow suit for much the same reasons as the solicitors. Requests by advocates for a new "pay" deal from the Scottish Executive with respect to criminal cases have provided the key to negotiations between the Scottish Legal Aid Board (SLAB) and the bar to introduce peer review. However, after preliminary discussions it emerged that there were insufficient written records of the work done by advocates to afford a robust basis for peer review of advocates. It has therefore been agreed that peer review of advocates and solicitor advocates will primarily be based on observation of their court work by trained peer reviewers. Even given the much smaller number of advocates regularly handling criminal cases (as opposed to solicitors), the logistics of such an operation are proving difficult to crack. The draft criteria are being worked on with an eye to a pilot program in 2008. It has been agreed that where an advocate fails his or her routine review, in place of an extended review (as occurs with solicitors) they will be tested by taking part in a mock trial with a real judge. 
Law Society (QAC). ${ }^{31}$ It recruited a team ${ }^{32}$ of peer reviewers from the solicitors' branch of the profession, arranged for them to be trained, and set in place the current review program. As on the criminal side, a set of twenty or so criteria were developed with input from senior practitioners. These were refined and tested on a series of anonymized files by the peer reviewers working together in pairs for training purposes. No significant problems were encountered..$^{33}$ At the end of the exercise it was concluded that (1) the criteria could be applied without significant difficulties to the files, (2) the criteria could be applied with reasonable consistency by different markers, and (3) no differences due to local legal culture were detected. ${ }^{34}$ These findings were reinforced in subsequent training sessions.

\section{OPERATIONALIZING PeER ReVIEW}

Early on it was agreed between the Law Society and the SLAB that up to five files per legal aid practitioner in a firm would be reviewed in the initial or "routine" review. ${ }^{35}$ The files randomly selected for review by the SLAB are sent to the reviewers who mark them against the agreed criteria and then return the files and mark sheets to the QAC. The QAC examines the reports from the reviewers ${ }^{36}$ and determines whether the firm should "pass" the first (or routine) review of its files. Most firms do, and they receive a report informing them that they have passed, but points from the reviewer's reports that need attention for the future are also identified. For the small minority that do not pass at the first time of asking (11 percent in the first cycle) a continuation may be given to clarify further points or an "extended" review (5 percent, in the first cycle) will be instigated. Such reviews take place on site and are conducted by two different reviewers from those who conducted the routine review. They may call for any legal aid file they choose and do not restrict themselves to merely five files. The purpose of an extended review is to see whether the potential flaws detected in the routine review are widely spread through the firm's files, or merely an aberration. Where a firm fails an extended review (fortunately a relatively rare event, only two percent in the first cycle) it has a period of one year in which to rectify the problems revealed by the routine and extended reviews before a "final" review is held. In the interim, a "special" review may be conducted. Although this process sounds somewhat threatening, and indeed may ultimately lead to a firm being refused permission to carry out poverty legal services/legal aid work in the future, the primary aim of peer review in Scotland is to boost

31 Its membership includes members from the Law Society, the SLAB, and the public (with some knowledge of quality assurance in other walks of life).

32 Initially, there were seventeen civil peer reviewers, with a range of specialties and spread across Scotland, all of them full-time practitioners doing the review work in their spare time (on a remunerated basis). Two reviewers resigned in mid-cycle following their appointment as part-time judges and in 2006, a further ten reviewers were appointed and trained.

33 As with the criminal files, a problem was found to arise as between scoring omissions from the file as "1"s, "C"s, or "2"s. The general conclusion was that in civil files the normal way to score omissions should be with a "C," but that too many "C"s would lead to a possible fail of the file. In consequence of the third finding, the Quality Assurance Committee (QAC) has been happy to accept that reviewers should not normally review firms operating in their own geographic locality, to obviate questions of conflict of interest.

35 However, it is the firm, rather than individual practitioners, that is approved by the peer review process. This leaves open the potential anomaly that a firm may pass its peer review overall, but one or two practitioners fail theirs.

36 Quite apart from files that are being double marked, it is common for a firm's files to be assessed by two or more reviewers with different specialties. 
the overall quality of the work being done by legal aid practitioners, rather than to weed out weaker firms. It follows that considerable emphasis is given in the process to passing on constructive feedback to the firms, with points of good practice being highlighted as well as points requiring attention for the future. In this respect, legal aid firms are merely following in the footsteps of large corporate firms or those that are members of a club or network of similar firms in the U.K. or European firms that have adopted independent file review quality assurance processes.

\section{THE OUTCOMES ${ }^{37}$}

By the end of September 2006, the number of firms registered to do civil legal aid and assistance work in Scotland had declined from the 752 registered in 2003 to $694,{ }^{38}$ and the reviewers had assessed 665 (99 percent) of them (with 171 double marked). Six-hundred and seventeen firms had been considered by the QAC with 87 (13 percent) continued for comment, 36 sent to extended review (5.4 percent), and 15 (2.3 percent) to final review. ${ }^{39}$ In the three years of the cycle, 1,514 practitioners had been marked and a total of 7,122 files reviewed. On average, the reviewers had assessed 89 practitioners each (although one had only done 54 while another had done 125). Since it is the exception rather than the rule for a practitioner to fail a routine review, the average number of practitioners failed by the reviewers was only 7.6 (8.5 percent) per reviewer since July 2004. Indeed practitioners were

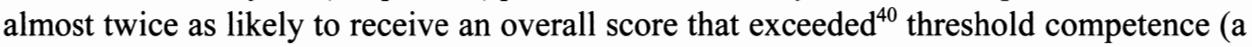
" 3 ") as they were to fail. On average, each reviewer had looked at 419 files, although again the range went from 217 to 588 . They had each failed on average 9.7 percent or 41 of these files each (with the range being from 24 to 68). In relation to distinction marks, 14.2 percent of practitioners were assessed as achieving a distinction grade, although only 10.3 percent of files received a distinction score.

\section{Peer Review in England And WaleS}

The position in Scotland can be compared with the position in England and Wales. The following snapshot of results, however, shows reviews carried out by looking at each firm or organization ("provider") which contracts with the Legal Services Commission, and not, as in Scotland, by looking at individual practitioners. By mid-November 2006, 98 peer reviewers had carried out reviews of 1016 civil legal aid providers in England and Wales. In the three years of the cycle, a total of 26,132 files were reviewed. On average the reviewers had each assessed 10.37 providers (although the number of reviews conducted by individual peer reviewers ranged between 1 and 53). It is unusual for a provider to fail a review; of the 1016 reviews conducted since August 2003 only 207 (20.37 percent) received a failing grade. Of these only 16 (1.57 percent) received the worst grade of "failure in performance." Four-hundred and seventy-six (46.85 percent) satisfied the minimum

The data in this section is available to the author from his participation in the QAC and his role as research adviser to the SLAB, which entailed the training of the peer reviewers and monitoring the consistency of their marking.

38 Of which 20 had effectively ceased to do any legal aid work.

39 Five of these eventually chose not to undergo final review and instead withdrew from the civil legal aid and assistance schemes.

40 For example, a "4" or a " 5 ." Such scores are called distinction marks. 
expectation of "threshold competence." A substantial 296 providers (29.04 percent) received grades of "competence plus." However, only 38 (3.74 percent) were recognized as having attained "excellence." Crime was also considered over the same period in England and Wales. The following figures provide an overview of grades given since March 2005 on all categories assessed in England and Wales.

Initial Rating for All Supplier Peer Reviews Conducted After 01/04/2005

\begin{tabular}{|c|c|c|c|c|c|c|c|c|c|c|c|}
\hline & & & & & 2 & & 3 & & & & 5 \\
\hline Category & $\begin{array}{c}\text { Total PR } \\
\text { in } \\
\text { Category }\end{array}$ & & $\%$ & & $\%$ & & $\%$ & & $\%$ & & $\%$ \\
\hline Community Care & 17 & 3 & 17.7 & 8 & 47.1 & 6 & 35.3 & 0 & 0 & 0 & 0 \\
\hline Crime* & 205 & 3 & 1.46 & 103 & 50.2 & 80 & 39 & 18 & 8.78 & 1 & 0.49 \\
\hline Debt & 51 & 3 & 5.88 & 17 & 33.3 & 23 & 45.1 & 8 & 15.7 & 0 & 0 \\
\hline Employment & 21 & 1 & 4.76 & 4 & 19.1 & 8 & 38.1 & 7 & 33.3 & 1 & 4.76 \\
\hline Family & 118 & 3 & 2.54 & 40 & 33.9 & 57 & 48.3 & 17 & 14.4 & 1 & 0.85 \\
\hline Housing & 55 & 5 & 9.09 & 16 & 29.1 & 27 & 49.1 & 7 & 12.7 & 0 & 0 \\
\hline Immigration & 49 & 4 & 8.16 & 10 & 20.4 & 21 & 42.9 & 13 & 26.5 & 1 & 2.04 \\
\hline Mental Health & 30 & 1 & 3.33 & 5 & 16.7 & 17 & 56.7 & 7 & 23.3 & 0 & 0 \\
\hline Welfare Benefits & 34 & 1 & 2.94 & 8 & 23.5 & 24 & 70.6 & 1 & 2.94 & 0 & 0 \\
\hline $\begin{array}{l}\text { Total PR in All } \\
\text { Categories }\end{array}$ & 580 & 24 & 4.14 & 211 & 36.4 & 263 & 45.3 & 78 & 13.5 & 4 & 0.69 \\
\hline
\end{tabular}

*It should be noted that some categories have not had a large number of reviews carried out, therefore care should be taken not to draw inferences from categories with small numbers of reviews. It should also be noted that the Crime sample is not randomly drawn. A large portion of these results have been undertaken for Very High Cost Cases suppliers. Results from these reviews are likely to be significantly better than the national benchmark. Therefore the results may not reflect the quality distribution across the supplier base as a whole.

\section{CONSISTENCY ISSUES}

Just as with academic assessments or grading, we should expect to see natural variations between markers, with some more predisposed to award failing or distinction marks than 
others. ${ }^{41}$ In Scotland, in the three-year cycle, steps were taken to counter these tendencies through the provision of six monthly debrief and feedback sessions. At the end of the cycle, fourteen of the sixteen operating reviewers were within 4 percent of the group norm (and eight were within 2.5 percent) for file fail marks. In relation to distinction marks for files, 12 of the reviewers were within 4 percent of the group norm (and nine were within 2.5 percent). Both in relation to the fail scores and distinction scores, there was a reduced range from the marking of the reviewers in the early stages of the cycle. ${ }^{42}$ These figures indicate that over the complete cycle, the greater familiarity of the reviewers with the procedures and with each others' marking has led to a greater cohesion and consistency in the marking around the group norms for failings and distinctions.

A preliminary scrutiny of the double-marked files suggests that in two-thirds of cases markers agreed on the overall score given to a file and in over 85 percent of cases there was agreement as to whether the file should pass or not. Despite this degree of consistency between markers, there are indications that if a reviewer has a low or high overall number of fail or distinction scores in comparison with the average for all reviewers, this will be reflected in situations where a file is double marked. Thus, those whose overall scores for the cycle suggest that they are soft markers (because they tend to fail a smaller percentage of files than the bulk of their colleagues) will tend to award a lower mark to a file that is being double or treble marked than a reviewer who is nearer to or above the group norm for file failings. Equally, reviewers whose distinction marks are somewhat above the group norm and are thus perceived as being more generous than their colleagues will tend to award a higher mark to a double-marked file than a reviewer who is nearer to or below the group norm for distinction scores.

It is too early to assess all the lessons to be learned from the Scottish civil peer review program. What has emerged is that the overall quality of the service provided, and of the providers themselves is, reassuringly high, with less than 10 percent of files and providers failing even their routine reviews. ${ }^{43}$ Moreover, the errors that emerge from the files are more often failures in communication or in the application, or explanation to the client, of the legal aid scheme. Errors in advice on the law, professional negligence, or professional misconduct ${ }^{44}$ are fortunately relatively uncommon.

In England and Wales some issues of consistency are dealt with though a system of representations which providers may make on the initial draft reports of the reviewers. These

4i Markers also vary as to the use of half marks or the use of really high or really low marks. Both were true of the reviewers. Most do not use half marks, but a significant minority have done so. Again, overall the reviewers in marking files used a " 5 " less often than they used a " 1 ," but neither score was used very frequently. Thus all the reviewers except one had given a " 1 " (the average being 3.7 and the range from one to eleven). However, eight reviewers had never awarded a " 5 " for a file and of the eight who had, the average was 2.25 (and the range was from one to seven).

After the first six months of the cycle, only eight of the 17 reviewers were within 4 percent of the group norm for file failures (and only two were within 2.5 percent). In relation to distinction marks, only four of the reviewers were within 4 percent of the group norm (and only one within 2.5 percent).

43 Since routine reviews only cover five files per practitioner, there is always the risk that one bad file will distort the picture of a practitioner's overall quality. Extended reviews cover considerably more files than routine reviews and therefore provide a fairer and more rounded picture of the practitioner's overall quality of work.

$44 \quad$ Including money laundering offences. 
give reviewers an opportunity to consider any misunderstandings of the files read and also the views of the practitioners who worked on them. Below is a chart showing the percentage of gradings which have risen as a result of representations from providers.

Representations data using Initial Rating

\begin{tabular}{|l|c|c|}
\hline & & $\%$ \\
\hline No. of reps made & 86 & \\
\hline Moved up & 15 & 17.44 \\
\hline Stayed the same & 71 & 82.56 \\
\hline Moved down & 0 & \\
\hline
\end{tabular}

Data compiled - 18 December 2006

Over the years, there have been a number of studies in the United States, ${ }^{45}$ and England and Wales ${ }^{46}$ calling into question the quality of work of poverty legal services lawyers, but rarely utilizing peer review and always with a limited sample of lawyers. However, in the last decade several new studies in England and $\mathrm{Wales}^{47}$ seem to be painting a more positive picture. The civil legal aid and assistance peer review cycle in Scotland not only reinforces this positive picture, but it is also possibly the first successful attempt to assess the quality of the total population of poverty lawyers in a country. ${ }^{48}$

\section{CONCLUSION}

The experience of the peer review studies in England and Wales, and Scotland to date suggests that peer review based on files, an agreed set of criteria, and trained reviewers, can deliver an effective quality assurance program in the U.K. Work is continuing to reduce as far as possible the potential for detriment to the livelihood of practitioners or the effect on clients through natural variations in approaches to marking by the reviewers. Work is also ongoing in seeking to extend peer review from files to the observation of interview or court performances. In short, as in academia, the quest continues apace for effective, fair, and transparent methods for assessing quality of performance in lawyers.

One side-effect of the peer review system in England and Wales has been the production guides by the peer reviewers as a result of what they have found in their assessments. The

See e.g. Abraham S. Blumberg, "The Practice of Law as a Confidence Game" (1967) 1 Law \& Soc'y Rev. 15; Carl J. Hosticka, "We Don't Care About What Happened, We Only Care About What is Going to Happen: Lawyer-Client Negotiations of Reality"(1979)26 Social Problems 599; Michael McConville \& Chester L. Mirsky, "Criminal Defense of the Poor in New York City" (1986) 15 N.Y.U. Rev. L. \& Soc. Change 581; Michael McConville \& Chester Mirsky, "Lawyering for the Poor in New York's Criminal Courts" (1987) 12 Hold. L.R. 22.

See e.g. John Baldwin \& Michael McConville, Negotiated Justice: Pressures to Plead Guilty (London: M. Robertson, 1977); Doreen J. McBarnet, Conviction: Law, the State and the Construction of Justice (London: Macmillan, 1981); Mike McConville et al., Standing Accused: The Organisation and Practices of Criminal Defence Lawyers in Britain (New York: Oxford University Press, 1994). 
Family Peer Review Panel and Institute of Advanced Legal Studies published a guide, "Improving your Quality: Family," that details common quality issues identified by peer reviewers in July $2007 .{ }^{49}$ These quality issues contribute to the reasons why organizations score a lower rating at peer review. The guides have also been published in these categories of law: crime, debt, welfare benefits, employment, immigration, and mental health. These guides have proved to be extremely popular with providers and networks.

However, the long-term impact of the widespread pursuit of quality assurance in the guise of peer review for the poverty legal services sector of the profession remains to be seen. Peer review is expensive to implement, and since it will certainly increase pressure on lawyers to keep better files, the cost may rise further if the profession succeeds in passing the cost of this to the public purse which funds legal aid. On the other hand, greater efficiency by the profession will reduce costs overall and deliver a better service to the public. Further research should also concentrate on how quality and cost intertwine in the changing world of legal services.

49 U.K., Legal Services Commission, Improving Your Quality: Family, online: Legal Services Commission $<$ http://www.legalservices.gov.uk/docs/cls_main/Family_Guide_Brochure_To_print_29_June_07_ gt.pdf $>$. 


\section{ANNEX A \\ Peer Review Civil ANd Family CRiteria}

\section{A. Communication:}

Please circle one only

1. How well does the adviser appear to have understood the client's $\begin{array}{llllll}1 & 2 & 3 & 4 & 5\end{array}$ problem?

2. How effective were the adviser's communication and client-handling $\begin{array}{lllll}1 & 2 & 3 & 4 & 5\end{array}$ skills?

3. How effective were the adviser's fact and information-gathering $\begin{array}{llllll}1 & 2 & 3 & 4 & 5\end{array}$ skills?

4. How effectively was the client informed of:
(a) the merits (or not) of the claim, and
(b) all developments?

$\begin{array}{llllll}1 & 2 & 3 & 4 & 5 & \text { N/A } \\ 1 & 2 & 3 & 4 & 5 & \text { N/A }\end{array}$

\section{B. The advice:}

1. How legally correct was the advice given?

2. How appropriate was the advice to the client's instructions?

3. How comprehensive was the advice? (For Family, see over)

4. Was the advice given in time/at the right time?

$\begin{array}{llllll}1 & 2 & 3 & 4 & 5 & \text { N/A } \\ 1 & 2 & 3 & 4 & 5 & \text { N/A } \\ 1 & 2 & 3 & 4 & 5 & \text { N/A } \\ & & & \text { Y } & \text { N } & \text { N/A }\end{array}$

\section{The work/ assistance:}

1. If no other work was carried out, was this appropriate?

2. If any further fact-finding work was carried out:
(a) how appropriate, and
(b) how efficiently executed was the work?

$\begin{array}{llllll}1 & 2 & 3 & 4 & 5 & \text { N/A } \\ 1 & 2 & 3 & 4 & 5 & \text { N/A }\end{array}$

3. If any other work was carried out:

(a) how appropriate, and

(b) how efficiently executed was the work?

$\begin{array}{llllll}1 & 2 & 3 & 4 & 5 & \mathrm{~N} / \mathrm{A} \\ 1 & 2 & 3 & 4 & 5 & \mathrm{~N} / \mathrm{A}\end{array}$

4. How effective in working towards what the client reasonably wanted/needed was any further work carried out?

5. If no disbursements were incurred, was this appropriate?

6. How appropriate were any disbursements incurred?

7. Where this is necessary did the adviser consider/advise on/act on an effective referral?

8. Throughout the file how effectively did the organization use resources?

9. Did the adviser or their work in any way prejudice the client? If yes, provide details below/overleaf.

Overall mark

Please write further necessary comments legibly and clearly on the additional paper provided. 


\section{Family}

B.3
(a) How comprehensive was the advice in relation to divorce?

$\begin{array}{llllll}1 & 2 & 3 & 4 & 5 & \text { N/A } \\ 1 & 2 & 3 & 4 & 5 & \text { N/A } \\ 1 & 2 & 3 & 4 & 5 & \text { N/A }\end{array}$
(c) How comprehensive was the advice in relation to ancillary relief?
(d) How comprehensive was the advice in relation to injunction?

$\begin{array}{llllll}1 & 2 & 3 & 4 & 5 & \text { N/A } \\ 1 & 2 & 3 & 4 & 5 & \text { N/A }\end{array}$
(e) How comprehensive was the advice overall? 


\section{ANNEX B \\ Criteria for Peer Review of Criminal Files}

Case complexity/difficulty: Exceptional/Demanding/Routine/Minor

Case Seriousness: Most Serious/Moderately Serious/Least Serious

Lead charge:

Other Charge(s):

Claim code(s):

\section{A. The File}

1. How effective is the composition of the file?

2. How appropriate is the level of information recorded:

(a) At investigation stage

(b) Post charge?

3. How appropriate was the management of the case throughout?

Comments:

\section{B. Communication}

1. How appropriate were the lawyer's communication and clienthandling skills?

2. How appropriately was the client informed of:

(a) The merits (or not) of their defence/case

(b) All developments (including conclusion)?

3. How appropriately was the lawyer's communication with others, including the CPS, defence counsel, etc.?

4. How timely was all communication?

Comments:

\section{Information and Fact Gathering}

1. How effective was the lawyer in seeking relevant information from the client?

2. How effective was the lawyer in seeking relevant information from the police and/or prosecution:
(a) At investigation stage
(b) Post charge?

3. How effective was the lawyer in seeking relevant information from others?

Comments:

\section{Advice and assistance}

Please circle one only

$\begin{array}{lllllll}1 & 2 & 3 & 4 & 5 & & \\ 1 & 2 & 3 & 4 & 5 & X & \text { N/A } \\ 1 & 2 & 3 & 4 & 5 & X & \text { N/A } \\ 1 & 2 & 3 & 4 & 5 & X & \text { N/A }\end{array}$

$\begin{array}{lllllll}1 & 2 & 3 & 4 & 5 & \mathrm{X} & \mathrm{N} / \mathrm{A} \\ 1 & 2 & 3 & 4 & 5 & \mathrm{X} & \mathrm{N} / \mathrm{A} \\ 1 & 2 & 3 & 4 & 5 & \mathrm{X} & \mathrm{N} / \mathrm{A} \\ 1 & 2 & 3 & 4 & 5 & \mathrm{X} & \mathrm{N} / \mathrm{A}\end{array}$


1. How good was the advice?

2. (a) How appropriate was advice on plea?

$\begin{array}{lllllll}1 & 2 & 3 & 4 & 5 & \mathrm{X} & \mathrm{N} / \mathrm{A}\end{array}$

(b) If (at any stage the client was advised to plead guilty, was the advice:
(i) too early
(ii) appropriate
(iii) too late?

3. How appropriate was advice on appeal?

$\begin{array}{lllllll}1 & 2 & 3 & 4 & 5 & \mathrm{X} & \mathrm{N} / \mathrm{A}\end{array}$

Comments:

\section{E. The work/assistance}

1. Was all work done that should reasonably have been done?

Y N $\quad \mathrm{X}$

If no, specify:

2. How effective was the work done in achieving the client's

$\begin{array}{llllll}1 & 2 & 3 & 4 & 5 & \mathrm{X}\end{array}$

(reasonable) objectives? 